\title{
Effect of Vitamin D Supplementation in the Prevention of Recurrent Pneumonia in Under-Five Children - Correspondence 2
}

Received: 3 December 2019 / Accepted: 10 February 2020 / Published online: 13 March 2020

(C) Dr. K C Chaudhuri Foundation 2020

To the Editor: We read with great interest the article by Singh et al. published in December 2019 issue of IJP [1]. We appreciate authors for carrying out this important study in the community. However, we would like to highlight a few points related to this study, which raise concerns regarding the validity of this study.

Authors have mentioned their study type as a communitybased randomized controlled trial (RCT), but the proper steps of RCT were not followed [2]. The authors didn't calculate the sample size (also highlighted in the accompanying editorial commentary), which is an initial obstacle that needs to be tackled before planning RCT. Furthermore, it is not clear from the methodology of the study, how the randomization was done? Whether authors generated randomization by computer or by random table, needs clarification.

After randomization, one group received oral vitamin D3 (Cholecalciferol) 30,000 IU quarterly for $1 \mathrm{y}$, and the other group received placebo powder in the form of finely ground sugar (castor sugar). Vitamin D was procured from a pharmaceutical company and was packaged in butter paper. The placebo group received castor sugar powder, which is sweeter in nature as compared to vitamin D3. It is recommended that both the drug and placebo should have similar color, odor, flavor, appearance, and should preferably be procured from the same manufacturer [3].

Authors have used World Health Organization (WHO) criteria for the definition of pneumonia; however if we see the Table 1, tachypnea was present only in $34 \%$ and $28 \%$ in group I and group C, respectively. Fast breathing as per age is the main criterion for the WHO definition of pneumonia [4].
Lastly, pediatric experience with Stoss therapy of 600,000 IU in infants with rickets shows significant hypercalcemia. Hypercalcemia has also been reported in infants who received a single dose of $300,000 \mathrm{IU}$ of vitamin D [5]. It is essential to monitor the serum level of vitamin $\mathrm{D}$ and calcium whenever a high dose of vitamin D is being used. Moreover, the citation of authors in support of a mega-dose of vitamin D by Kearns et al., is actually a systematic review in the adult population.

Prawin Kumar and Jagdish Prasad Goyal

Department of Pediatrics, All India Institute of Medical Sciences, Jodhpur, Rajasthan, India. E-mail: jpgoyal@ rediffmail.com

\section{References}

1. Singh N, Kamble D, Mahantshetti NS. Effect of vitamin D supplementation in the prevention of recurrent pneumonia in under-five children. Indian J Pediatr. 2019;86:1105-11.

2. Akobeng AK. Understanding randomized controlled trial. Arch Dis Child. 2005;90:840-4.

3. Wan M, Orlu-Gul M, Legay H, Tuleu C. Blinding in pharmacological trials: the devil is in the details. Arch Dis Child. 2013;98:656-9.

4. Cesur Y, Caksen H, Gündem A, Kirimi E, Odabas D. Comparison of a low and high dose of vitamin D treatment in nutritional vitamin D deficiency rickets. J Pediatr Endocrinol Metab. 2003;16:1105-9.

5. Revised WHO Classification and Treatment of Pneumonia in Children at Health Facilities: Evidence Summaries. Geneva: World Health Organ; 2014.

Publisher's Note Springer Nature remains neutral with regard to jurisdictional claims in published maps and institutional affiliations. 